\title{
Analisis Medan Magnet Bumi Sebelum dan Sesudah Kejadian Gempa (Studi Kasus: Gempa 18 November 2014 di Sabang)
}

\author{
Jein Sintia Dewi Ta'uno a*, Gerald H. Tamuntuan a, Seni H. J. Tongkukut a \\ aJurusan Fisika, FMIPA, Unsrat, Manado
}

\begin{tabular}{|c|c|}
\hline KATA KUNCI & A B S T R A K \\
\hline $\begin{array}{l}\text { anomali } \\
\text { medan magnet } \\
\text { prekursor gempa bumi }\end{array}$ & $\begin{array}{l}\text { Telah dilakukan penelitian untuk mengidentifikasi dan menganalisis } \\
\text { perubahan medan magnet bumi sebelum dan sesudah kejadian gempa } \\
18 \text { November } 2014 \text { di Sabang yang dapat dikenali sebagai prekursor } \\
\text { gempa bumi. Metode yang digunakan adalah perbandingan residu medan } \\
\text { magnet komponen } \mathrm{Z} \text { dan } \mathrm{H} \text {. Untuk memastikan anomali yang diperoleh } \\
\text { bukan berasal dari gangguan eksternal, data diverifikasi dengan Indeks } \\
\text { Dst. Hasil yang diperoleh menunjukkan bahwa anomali medan magnet } \\
\text { terjadi pada } 2 \text { dan } 8 \text { hari sebelum gempa. Anomali diduga kuat berasal } \\
\text { dari aktivitas litosfer yang berkaitan dengan retakan yang terjadi pada } \\
\text { batuan yang dialiri cairan yang mengandung material bersifat magnet } \\
\text { yang menyebabkan kenaikan nilai rasio medan magnet } \mathrm{Z} / \mathrm{H} \text {. }\end{array}$ \\
\hline
\end{tabular}

\begin{tabular}{l} 
K E Y W O R D S \\
\hline anomaly \\
magnetic field \\
earthquake precursor
\end{tabular}

TERSEDIA ONLINE

1 Agustus 2016

\begin{abstract}
A B S T R A C T
A research has been done to identify and analyze earth's magnetic field change before and after November 18 ${ }^{\text {th }}$, 2014 earthquake in Sabang that can be recognize as an earthquake precursor. Method that used ini this research was comparison of $\mathrm{Z}$ and $\mathrm{H}$ residu of magnetic's field. To ensure that anomaly identified were not of due to external disturbances that records, data were examined by Dst Index. The result of this research showed that magnetic's field anomaly were identified in 2 and 8 days before earthquake event. This anomaly was predicted from lithosphere that associated with rock's crack that flow by liquid that contains magnetic material cause increased of magnetic's field $\mathrm{Z} / \mathrm{H}$ rasio.
\end{abstract}

\section{Pendahuluan}

Secara geografis, Indonesia terletak pada pertemuan tiga lempeng besar dunia, yakni Lempeng Eurasia yang bergerak relatif ke selatan, Lempeng Indo-Australia yang bergerak relatif ke utara dan Lempeng Pasifik yang bergerak relatif ke barat. Ketiga lempeng ini bergerak relatif satu terhadap yang lainnya dengan kecepatan tertentu setiap tahunnya.. Hingga saat ini, belum ada metode yang tepat untuk memprediksi waktu dan tempat gempa bumi akan terjadi. Gempa bumi merupakan salah satu fenomena alam yang sering terjadi, karena adanya pelepasan energi yang terakumulasi akibat adanya perpindahan material dalam skala besar di dalam kerak bumi atau pergerakan elastik di daerah patahan untuk waktu tertentu (Purba, 2013). Walaupun gempa bumi belum bisa diprediksi secara pasti, tanda-tanda kejadian gempa dapat dikenali melalui pengamatan secara berkesinambungan. Pemantauan gejala atau tanda awal kejadian gempa bumi antara lain dapat dilakukan dengan melihat perubahan medan magnet sebelum terjadinya gempa.

Beberapa penelitian dalam hal prekursor gempa bumi telah dilakukan oleh para ahli kebumian. Salah satu penelitian berhubungan 
dengan anomali medan magnet sebelum gempa bumi yaitu yang dilakukan oleh Hobara dkk (2003). Penelitian ini menganalisis karakteristik anomali magnetik ULF sebelum gempa bumi dengan menggunakan 3 kejadian gempa pada waktu dan tempat berbeda, yakni gempa di Pulau Izu, gempa Guam, dan gempa Biak. Dari penelitian ini diketahui bahwa terjadi peningkatan rasio medan magnet komponen $\mathrm{Z}$ dan $\mathrm{H}$ yang signifikan sebulan sebelum terjadinya gempa bumi. Nampak bahwa kejadian gempa bumi telah diawali dengan adanya anomali medan magnet di daerah kejadian gempa. Salah satu daerah yang rawan dengan kejadian gempa bumi adalah Sumatera. Beberapa kejadian gempa bumi yang terjadi di daerah ini memiliki magnitudo yang cukup besar, yakni dalam kisaran 4-6 SR (Saroso, 2008). Perhitungan nilai rasio medan magnet dalam penelitian ini menggunakan persamaan polinomial orde 5 , seperti yang pernah dilakukan oleh Fauzi (2008) untuk melihat anomali medan magnet sebelum dan sesudah gempa vulkanik Gunung Lokon pada tahun 2011. Rasio ini diperoleh dengan membandingkan residu medan magnet komponen $\mathrm{Z}$ dan $\mathrm{H}$. Penelitian ini dilakukan untuk menganalisis dan mengidentifikasi perubahan nilai kemagnetan sebelum dan sesudah gempa 18 November 2014 di Sabang.

\subsection{Kondisi Tektonik Sumatera}

Sumatera adalah daerah dengan intensitas dan magnitudo yang besar. Menurut Peta Seismisitas Gempa di Indonesia tahun 2004-2006, dengan magnitudo $\geq 6 \mathrm{SR}$, daerah Sumatera memiliki magnitudo dalam rentang 6-8 SR.

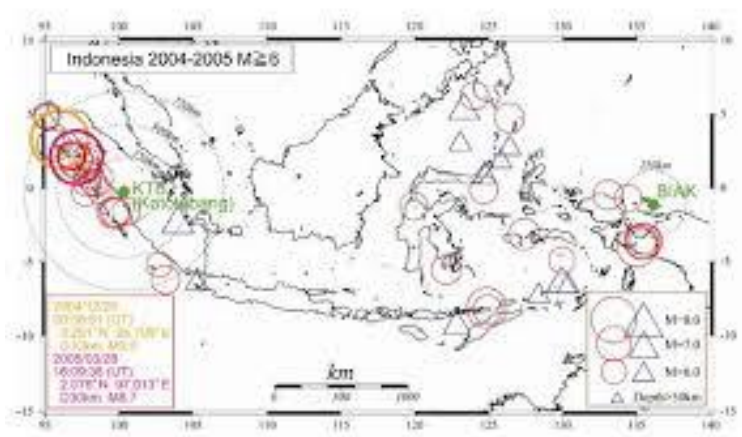

Gambar 1. Peta seismisitas gempa di Indonesia tahun 2004-2006, magnitudo $\geq 6$ SR (Saroso, 2008)

\subsection{Kemagnetan Bumi}

Secara sederhana, medan magnet bumi dapat digambarkan sebagai medan magnet yang ditimbulkan oleh batang magnet besar yang ada di dalam inti bumi, yang letaknya tidak berimpit dengan garis utara selatan geografis bumi. Ada beberapa alasan sehingga bumi memiliki medan magnetik, di antaranya:

1. Kecepatan rotasi Bumi yang tinggi,

2. Proses konveksi di mantel dengan inti luar bumi, dan

3. Inti dalam yang konduktif, kaya kandungan besi.
Komponen medan magnet bumi dapat diilustrasikan dalam bentuk kubus, seperti yang dapat dilihat pada Gambar 2. Komponen-komponen yang digunakan pada prinsip magnetik berdasar pada sumbu x (utara geografis) dan sumbu y (timur geografis).

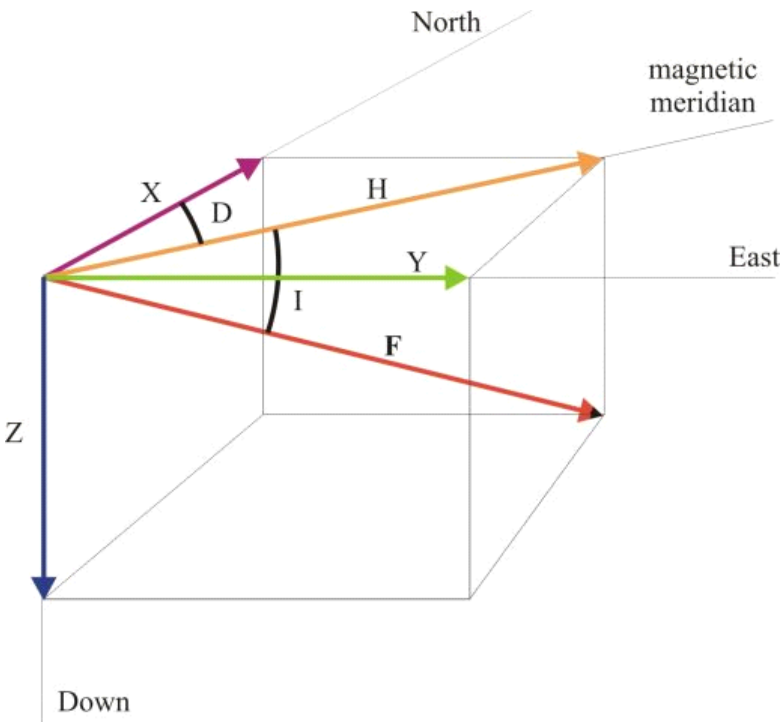

Gambar 2. Variabel magnetik: intensitas total (F), intensitas horizontal $(\mathrm{H})$, komponen utara (x), komponen timur (y), komponen vertikal/kedalaman (z), inklinasi geomagnetik (I), dan D deklinasi geomagnetik (Reynold, 1995).

\subsection{Indeks Dst}

Indeks Dst merupakan indeks kekuatan badai geomagnet dengan resolusi 1 jam. Ketika terjadi badai geomagnetik, akan terjadi penurunan atau pelemahan medan magnet. Badai geomagnetik sangat kuat ditandai dengan nilai Indeks Dst di bawah -300 nT dan biasanya diakibatkan oleh Iontaran massa korona tipe halo yang mengarah ke bumi (Margiono, 2012). Indeks Dst diperoleh dari rata-rata pengukuran komponen horizontal dari medan magnet bumi dari 4 observatorium geomagnet di dekat ekuator. Indeks Dst inilah yang pada penelitian ini akan digunakan untuk melihat apakah anomali yang terjadi dipengaruhi oleh badai magnetik atau merupakan gangguan yang berasal dari litosfer.

\section{Metode}

Penelitian ini menggunakan data variasi medan magnet bumi komponen $\mathrm{Z}$ dan $\mathrm{H}$ yang diperoleh melalui Stasiun Geofisika Winangun. Data merupakan hasil pengukuran selama bulan OktoberDesember 2014. Data medan magnet yang diperoleh merupakan data digital per detik yang selanjutnya dirata-ratakan menjadi data per jam (hourly mean value). Data kemudian diinterpolasikan dengan persamaan polinomial orde 5 untuk memperoleh kurva yang mulus. Dari raw data dan hasil interpolasi polinomial, maka 
diperoleh nilai residu medan magnet. Pesamaan polinomial ditunjukkan dalam persamaan:

$$
f(x)=a_{n} x^{n}+\cdots+a_{2} x^{2}+a_{1} x+a_{0}
$$

dengan $a_{0}, a_{1}, a_{2}, \ldots, a_{n}$ adalah parameter yang akan dicari berdasarkan titik data, $n$ adalah derajat (orde) dari persamaan polinomial, dan $x$ adalah variabel bebas. Nilai residu medan magnet diperoleh dari selisih antara data hasil pengukuran dan hasil interpolasi polinomial. Nilai residu medan magnet komponen $\mathrm{Z}$ dan $\mathrm{H}$ kemudian dibandingkan dan dianalisis, apakah anomali yang terjadi berkaitan dengan aktifitas ionosfer atau litosfer. Dalam analisis juga digunakan indeks Dst untuk melihat apakah anomali yang muncul berkaitan dengan badai geomagnetik atau tidak berkaitan dengan badai geomagnetik.

\section{Hasil dan Pembahasan}

Pada kasus gempa 18 November 2014 di Sabang, data yang digunakan adalah data medan magnet komponen $\mathrm{H}$ dan $\mathrm{Z}$ pada bulan Oktober -
Desember 2014. Data ini memiliki frekuensi pengukuran yang kecil yaitu $1 \mathrm{~Hz}$. Data yang diberikan merupakan data hasil pengukuran tiap detik, sehingga untuk meneruskan proses pengolahan data, setiap data yang ada dibuat ratarata per jam yang kemudian diolah dengan interpolasi polinomial orde 5. Ruhimat dkk (2008) mengatakan bahwa pola variasi harian medan magnet akan berbentuk kurva yang halus jika tidak mengalami gangguan dan pola pada tiap hari akan sama, yaitu meningkat pada pagi hingga siang hari, dan menurun pada siang hingga malam hari. Pola yang ditunjukkan pada Gambar 3 dan 4 tidak menunjukkan kurva yang halus, sehingga diduga bahwa terjadi gangguan pada medan magnet bumi. Dari nilai medan magnet hasil pengukuran dan hasil interpolasi polinomial, maka diperoleh nilai residu medan magnet pada masing-masing komponen. Perbadingan nilai residu medan magnet komponen $\mathrm{Z}$ dan $\mathrm{H}$ digunakan untuk mengetahui sumber gangguan medan magnet.

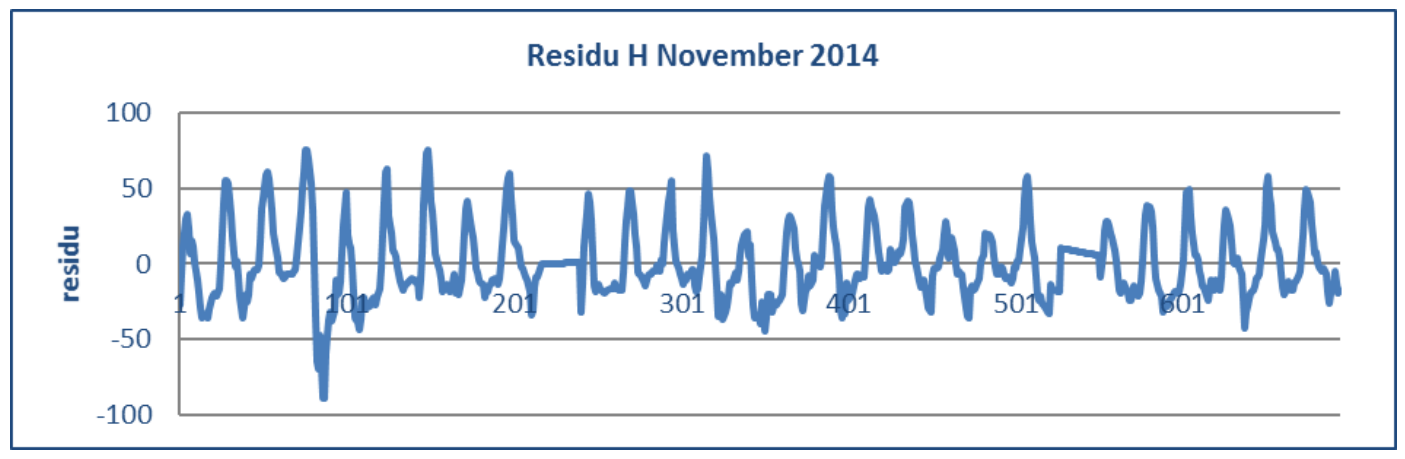

Gambar 3. Residu medan magnet komponen H November 2014 TUN

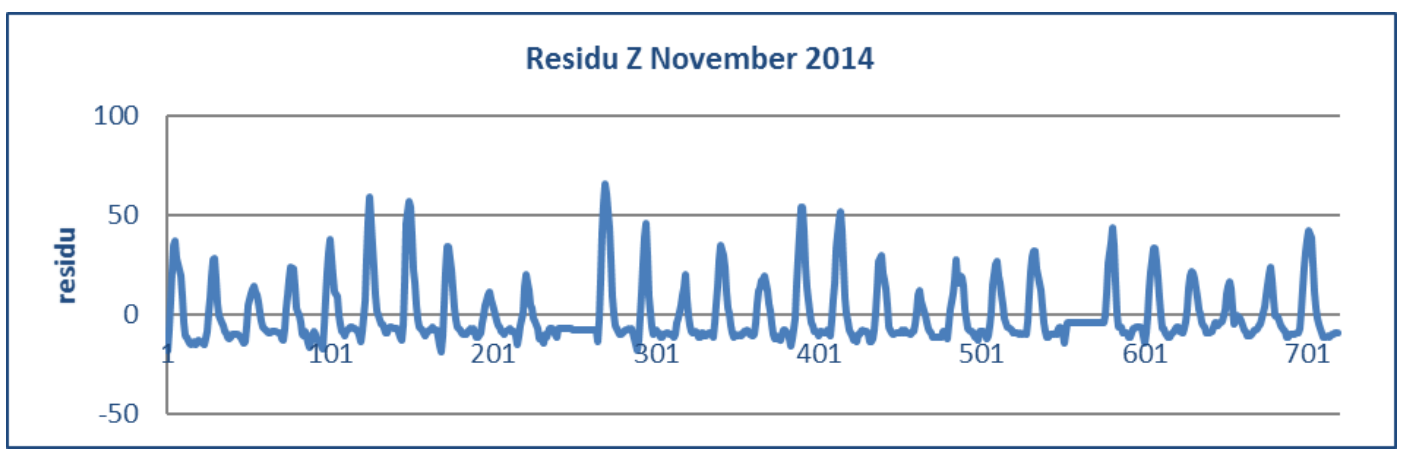

Gambar 4. Residu medan magnet komponen Z November 2014 TUN

Gambar 3 dan 4 menunjukkan nilai residu medan magnet pada komponen $\mathrm{H}$ dan $\mathrm{Z}$ untuk bulan November 2014. Sumbu y merupakan nilai residu dalam nT (nano Tesla) dan sumbu x sebagai waktu (jam). Nilai residu menunjukkan bahwa pada waktu sekitar kejadian gempa terjadi gangguan yang ditunjukkan dengan nilai residu yang berfluktuasi. Untuk mengetahui sumber gangguan pada medan magnet, maka dihitunglah nilai perbandingan residu komponen $\mathrm{Z}$ dan $\mathrm{H}$. perbandingan nilai dapat dilihat pada Gambar 5, 6 dan 7. Sumbu y mewakili nilai rasio dan sumbu $x$ mewakili waktu. Perbandingan yang ditunjukkan pada gambar merupakan perbandingan nilai $\mathrm{Z} / \mathrm{H}$ pada 1 bulan sebelum kejadian gempa sampai 1 bulan setelah kejadian gempa. 


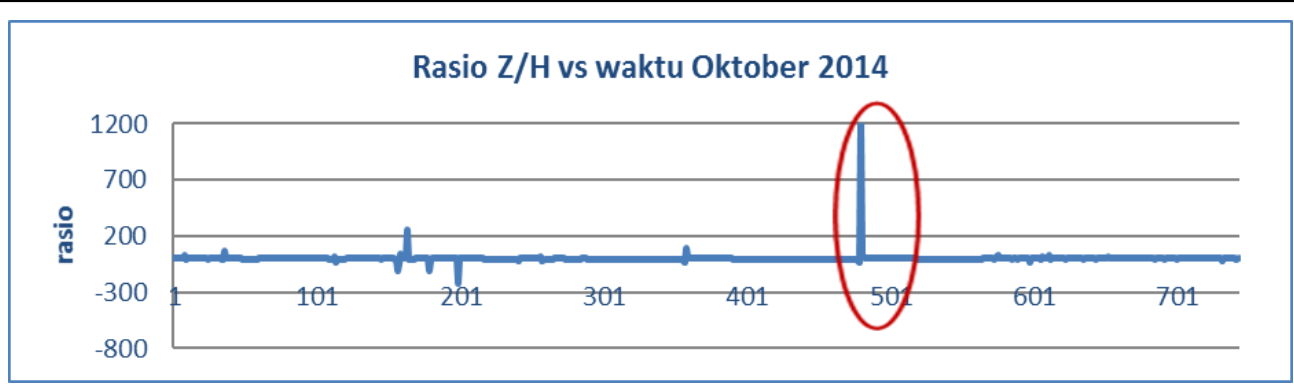

Gambar 5. Rasio Z/H Oktober 2014 TUN

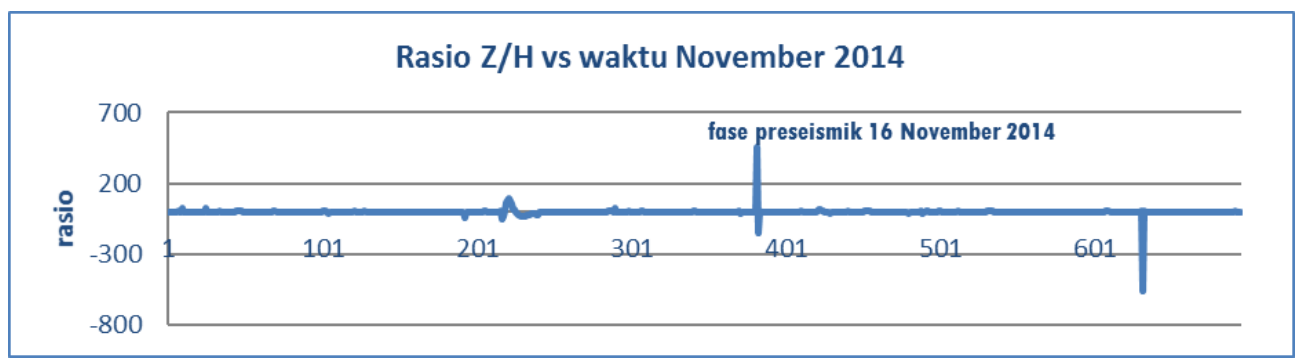

Gambar 6. Rasio Z/H November 2014 TUN

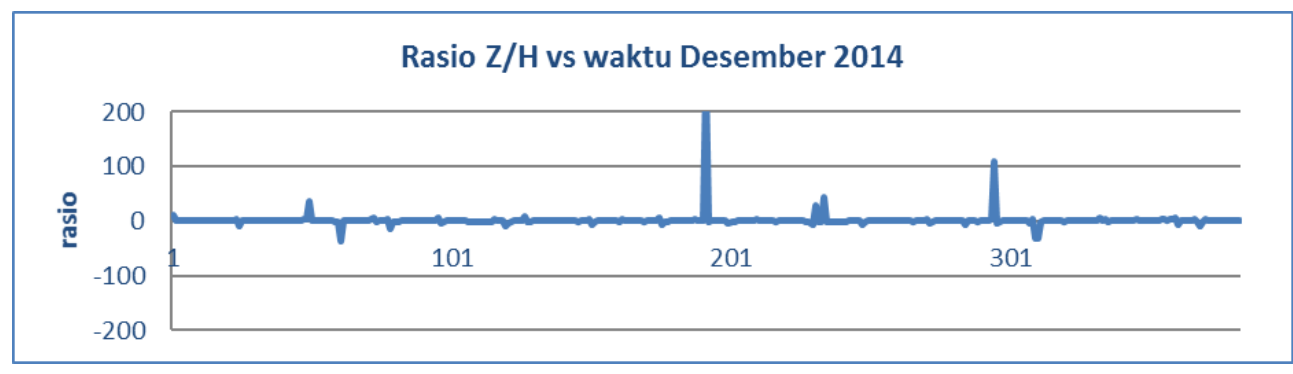

Gambar 7. Rasio Z/H Desember 2014 TUN

Dari Gambar 5 terlihat adanya peningkatan rasio mulai pada tanggal 21 Oktober 2014 (O0 UT), ketika nilai rasio menunjukkan angka yang sangat besar, yakni 1239 (lingkaran merah). Nilai ini jauh melebihi nilai rasio yang lainnya. Nilai Indeks Dst yang menunjukkan kejadian badai geomagnetik, pada tanggal 21 Oktober 2014 tidak menunjukkan terjadi badai magnetik, sehingga kenaikan ini tidak disebabkan oleh badai magnetik. Selanjutnya, pada waktu setelah kenaikan signifikan ini, nilai rasio medan magnet menunjukkan angka yang semakin mendekati nol.

Rasio kembali meningkat pada tanggal 10 November 2014 (4 UT) dan 16 November 2014 (22 UT). Ini diduga merupakan aktifitas preseismic yang berkaitan dengan gempa 18 November 2014 yang teridentifikasi pada 8 dan 2 hari sebelum gempa. Dari setiap anomali yang terlihat, hal yang paling dominan terjadi adalah peningkatan nilai rasio.
Peningkatan nilai rasio ini diduga kuat berkaitan dengan retakan yang terjadi pada batuan yang mengandung material bersifat magnet yang merubah nilai medan magnet komponen $Z$. perubahan yang terjadi ini meyebabkan terjadinya kenaikan pada medan magnet komponen $\mathrm{Z}$. Beberapa peak muncul pada tanggal 21 Oktober 2014, 10 dan 16 November 2014.

Nilai medan magnet diverifikasi dengan nilai Indeks Dst (Disturbance storm time) pada bulan November 2014 untuk mengetahui apakah terjadi badai magnetik atau merupakan hari tenang. Indeks Dst bulan November dapat dilihat pada Gambar 8. Sumbu x mewakili waktu (1-30 November 2014), sementara sumbu y mewakli nilai medan magnet hasil pengukuran dalam satuan nano Tesla (nT). Nilai yang ditujukkan pada Gambar 3 relatif stabil dengan kisaran nilai -30 sampai $30 \mathrm{nT}$. 


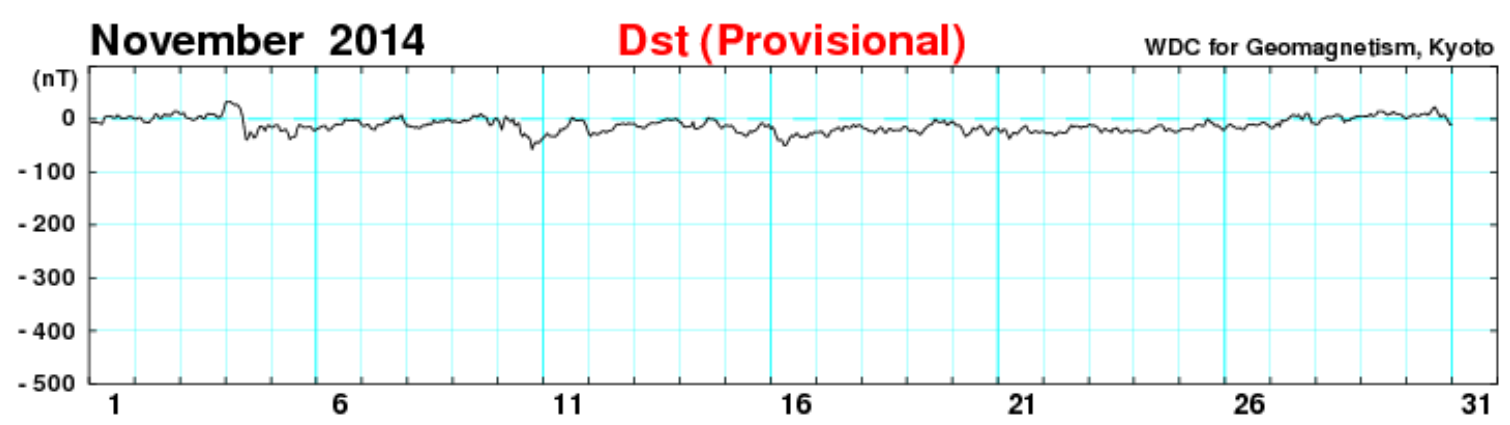

Gambar 8. Indeks Dst bulan November 2014

\section{Kesimpulan}

1. Anomali medan magnet gempa 18 November 2014 di Sabang muncul pada 8 sampai 2 hari sebelum kejadian gempa dengan nilai anomali mencapai 100-450 nT.

2. Anomali pada gempa 18 November 2014 di Sabang ditandai dengan peningkatan rasio $\mathrm{Z} / \mathrm{H}$ yang disebabkan oleh aktifitas litosfer dan terjadi pada saat bumi tidak mengalami badai magnetik.

3. Anomali yang muncul berkaitan dengan retakan yang terjadi pada batuan yang menyebabkan kenaikan nilai rasio.

4. Perubahan medan magnet dapat dijadikan sebagai prekursor gempa bumi.

\section{Daftar Pustaka}

Fauzi, K. 2012. Analisis Perubahan Nilai Kemagnetan Terhadap Aktifitas Vulkanik Gunung Lokon di Stasiun Pengamatan Magnet Tondano [Laporan Kerja]. Akademi Meteorologi dan Geofisika Jakarta.

Hobara, Y., Koons H. C., Roeder J. L., Yumoto K., dan Hayakawa. 2003. Characteristics of ULF Magnetic Anomaly Before Earthquakes. Physics and Chemistry of the Earth 29 (2004): 437-444.
Kurniawati, I. 2015. Penentuan Anomali ULF (UItra Low Frequency) Fase Praseismik untuk Prekursor Gempa Bumi di Laut Maluku [Skripsi]. Program Sarjana Terapan Geofisika Sekolah Tinggi Meteorologi Klimatologi dan Geofisika Tangerang Selatan.

Kyoto University. 2014. Geomagnetic Equatorial Dst Index. http://wdc.kugi.kyoto-u.ac.jp [22 Maret 2016].

Margiono, R. 2012. Aplikasi Filter Noise pada Rekaman Sinyal Magnet Bumi di Stasiun Geofisika Klas I Tangerang [Laporan Kerja]. Program Pendidikan Diploma III Jurusan Geofisika Akademi Meteorologi dan Geofisika Jakarta.

Purba, S. F. 2013. Pemisahan Anomali Geomagnet Terkait Gempa Bumi dari Pengaruh Aktivitas Matahari dengan Metode Polarisasi Sinyal ULF [Skripsi]. Universitas Pendidikan Indonesia.

Reynold, J. M. 1995. An Introduction to Applied and Environmental Geophysics. Willey, Chichester, UK.

Ruhimat, M., La Ode M. M., Eddy I. S., Dodi S., Obay S., dan Cecep S. 2008. Analisis Perubahan Medan Magnet Bumi Menjelang Gempa Bumi di Biak Tahun 1996.

Saroso, S. 2010. Analisis Fraktal Emisi Sinyal ULF dan Kaitannya dengan Gempa Bumi di Indonesia. Semnas Matematika dan Pendidikan Matematika. Hal 400-406. 